\title{
Daytime ozone loss term in the mesopause region
}

\author{
Mikhail Y. Kulikov ${ }^{1}$, Mikhail V. Belikovich ${ }^{1}$, Mykhaylo Grygalashvyly ${ }^{2}$, Gerd R. Sonnemann ${ }^{2,3}$, \\ Tatiana S. Ermakova ${ }^{1}$, Anton A. Nechaev ${ }^{1}$, and Alexander M. Feigin ${ }^{1}$ \\ ${ }^{1}$ Institute of Applied Physics of the Russian Academy of Sciences, 46 Ulyanov Str., 603950 Nizhny Novgorod, Russia \\ ${ }^{2}$ Leibniz Institute of Atmospheric Physics at the University of Rostock in Kühlungsborn, Schloss-Str. 6, \\ 18225 Ostseebad Kühlungsborn, Germany \\ ${ }^{3}$ Max Planck Institute for Solar System Research, Max-Planck-Str. 2, 37191 Katlenburg-Lindau, Germany \\ Correspondence to: Mikhail Y. Kulikov (mikhail_kulikov@mail.ru)
}

Received: 8 April 2017 - Accepted: 24 April 2017 - Published: 23 May 2017

\begin{abstract}
For the retrieval of atomic oxygen via ozone observations in the extended mesopause region under sunlight conditions, two assumptions are used: first, the photochemical equilibrium of ozone and, second, that the ozone losses are dominated by ozone's dissociation from solar UV radiation, silently ignoring the $\mathrm{O}_{3}$ destruction by atomic hydrogen. We verify both by 3-D modeling. We found that ozone approaches photochemical equilibrium at $75-100 \mathrm{~km}$ for daytime conditions. Hence, the first assumption is valid. However, the reaction of ozone with atomic hydrogen was found to be an important loss process and should not be omitted in retrieving atomic oxygen.
\end{abstract}

Keywords. Atmospheric composition and structure (middle atmosphere - composition and chemistry)

\section{Introduction}

Satellite measurements of atomic oxygen in the MLT (mesosphere-lower thermosphere) region are based on two major assumptions: (1) about the ozone's photochemical equilibrium and (2) about the solar UV dissociation as the main ozone loss at these levels. For several decades, these assumptions have been used to determine the distributions of atomic oxygen at specific heights of the MLT via satellite and rocket measurements of ozone and airglow emissions (e.g., Pendleton et al., 1983; Evans and Llewellyn, 1973; Evans et al., 1988; Thomas, 1990; Mlynczak et al., 2007, 2013a, b, 2014; Smith et al., 2010; Siskind et al., 2015). Kulikov et al. $(2006,2009)$ proposed algorithms for the simultaneous retrieval of $\mathrm{O}, \mathrm{H}, \mathrm{HO}_{2}$ and $\mathrm{H}_{2} \mathrm{O}$ by joint $\mathrm{OH}$ and
$\mathrm{O}_{3}$ satellite measurements by implementing the assumption about the photochemical equilibrium of ozone. Mlynczak et al. (2013b) also used this assumption to derive exothermic chemical heat in the MLT region. Grygalashvyly et al. (2014) and Sonnemann et al. (2015) used these assumptions in their derivation of analytical solutions and in an analysis of $\mathrm{OH}^{*}$ layer morphology.

The problems involved in the deviations from photochemical equilibrium that ozone experiences during the night were discussed in Kulikov et al. (2017). Under sunlight conditions, the photochemical lifetime of ozone is assumed to be $\sim 2 \mathrm{~min}$ in this region due to photodissociation in the UV Hartley band. At almost all daytime zenith angles (except periods near terminators), the photochemical lifetime is much smaller than the characteristic transport times by advection and diffusion. Hence, the photochemical equilibrium of ozone holds in the mesopause during the daytime. However, ozone losses during the daytime are not so obvious.

The balance of photochemical ozone at these altitudes is determined by three primary reactions:

$\mathrm{O}\left({ }^{3} \mathrm{P}\right)+\mathrm{O}_{2}+M \rightarrow \mathrm{O}_{3}+M, \mid k_{1}$,

$\mathrm{O}_{3}+h v \rightarrow \mathrm{O}_{2}+\mathrm{O}\left({ }^{1} \mathrm{D},{ }^{3} \mathrm{P}\right), \mid J_{\mathrm{O}_{3}}=J_{1}+J_{2}$,

$\mathrm{O}_{3}+\mathrm{H} \rightarrow \mathrm{O}_{2}+\mathrm{OH}, \mid k_{2}$,

where $k_{1}$ and $k_{2}$ are corresponding reaction rates and $J_{\mathrm{O}_{3}}$ is the total dissociation rate of ozone, which is a sum of two branches, $J_{1}$ and $J_{2}$, and $M$ is air number density. The reaction rate of $\mathrm{O}_{3}$ with $\mathrm{O}$ is several orders smaller than that of $k_{2}$ in the extended mesopause region; therefore, the reaction of ozone with atomic oxygen amounts to less than $10 \%$ of the total ozone loss (Smith et al., 2008). Consequently, we can leave it out of the total ozone balance. 
Under photochemical equilibrium of ozone (assuming it to be valid),

$\mathrm{O}_{3} \cong \frac{k_{1} \cdot \mathrm{O} \cdot \mathrm{O}_{2} \cdot M}{J_{\mathrm{O}_{3}}+k_{2} \mathrm{H}}$.

Hence, for $\mathrm{O}$ retrieval by ozone observation via Reaction ( $\mathrm{R} 1)$, additional information about $\mathrm{H}$ is required. In Evans and Llewellyn (1973) and Thomas (1990), atomic hydrogen concentration is determined by $\mathrm{OH}^{*}$ airglow emission, since Reaction (R3) is a primary source for excited hydroxyl. Kulikov et al. (2006, 2009) determines the values of $\mathrm{O}$ and $\mathrm{H}$ jointly as the result of an algebraic equations system that is solved under the conditions of the joint photochemical equilibrium of $\mathrm{O}_{3}, \mathrm{OH}$ and $\mathrm{HO}_{2}$.

Nevertheless, in the majority of investigations (e.g., Pendleton et al., 1983; Evans et al., 1988; Mlynczak et al., 2007, 2013a, b, 2014; Smith et al., 2010; Siskind et al., 2015), the second term in the denominator of Reaction (R1) is omitted (i.e., $\mathrm{O}_{3}=k_{1} \cdot \mathrm{O} \cdot \mathrm{O}_{2} \cdot M / J_{\mathrm{O}_{3}}$ ) and only ozone observations are utilized to estimate atomic oxygen concentrations.

In this case, Reaction (R3) is supposed to be small relative to the dissociation of ozone: $k_{2} \cdot \mathrm{H} \cdot \mathrm{O}_{3} \ll J_{\mathrm{O}_{3}} \cdot \mathrm{O}_{3}$ (e.g., Smith and Marsh, 2005); this is, according to Pendleton et al. (1983), equivalent to $\mathrm{H} \ll 5 \times 10^{8} \mathrm{~cm}^{-3}$. In these cases the uncertainty of atomic $\mathrm{O}$ density is assumed to be primarily the result of uncertainties regarding ozone measurements and reaction rates of Reaction (R1). For example, in the case of the SABER (Sounding of the Atmosphere using Broadband Emission Radiometry) instrument, such uncertainty amounts to $30 \%$ (Mlynczak et al., 2013).

However, the concentration of $\mathrm{H}$ may exceed the value of $10^{8} \mathrm{~cm}^{-3}$ in the mesopause. For example, according to SME (Solar Mesosphere Explorer) satellite observations, the maximum level of atomic hydrogen is $\sim 2-5 \times 10^{8} \mathrm{~cm}^{-3}$ at $80-$ $93 \mathrm{~km}$ (Thomas, 1990). Thus, the error in O values due to omission of Reaction (R3) is comparable to or exceeds $30 \%$ $\left(\frac{\delta \mathrm{O}}{\mathrm{O}}=\frac{k_{2} \cdot \mathrm{H}}{J_{\mathrm{O}_{3}}}\right)$. This is in agreement with previous theoretical works which show that at $80-90 \mathrm{~km}$ the losses of ozone due to Reaction (R3) are comparable (Moreels et al., 1977) or even exceed (Allen et al., 1984) ozone losses via photodissociation (Reaction R2). Thus, the problem of correct retrieval of atomic oxygen by ozone measurements is still unresolved and needs more detailed research with respect to seasonal and latitudinal variation.

In this work, we conducted a global investigation, based on the 3-D chemistry-transport model (CTM) of both assumptions: the photochemical equilibrium of ozone and the relative significance of different sources of ozone losses in the upper mesosphere-lower thermosphere region in the daytime. The paper is structured as follows: in the next section, the model is briefly described; Sect. 3 presents the results and discussion of our calculations, followed by concluding remarks in the last section.

\section{Model and calculations}

For our calculations, we used the global 3-D CTM of the middle atmosphere developed by the Leibniz Institute of Atmospheric Physics (IAP). The model was particularly designed to investigate the spatiotemporal structure of phenomena in the MLT region and, specifically, in the extended mesopause region. The model contains 3-D advective and vertical diffusive transport (turbulent and molecular). The grid-point model extends from the ground up to the lower thermosphere $(0-150 \mathrm{~km} ; 118$ pressure-height levels). The horizontal resolution amounts to $5.625^{\circ}$ latitudinally and $5.625^{\circ}$ longitudinally. The chemistry module consists of 19 constituents, 49 chemical reactions, and 14 photodissociation reactions. The CTM has been described in numerous papers (e.g., Sonnemann et al., 1998; Körner and Sonnemann, 2001; Grygalashvyly et al., 2009, 2011, 2012). It was validated, particularly for ozone, in a number of papers with measurements (Hartogh et al., 2004, 2011; Sonnemann et al., 2006a, b, 2007). Three-dimensional fields of the temperature and winds are used from the Canadian Middle Atmosphere Model (CMAM) for the year 2000 (de Grandpre et al., 2000; Scinocca et al., 2008).

We calculated the annual variation of the spatiotemporal distributions of the relative deviation $\left(\mathrm{O}_{3} / \mathrm{O}_{3 \text { eq }}-1\right)$, where $\mathrm{O}_{3}$ is the ozone value calculated by the model and $\mathrm{O}_{3 \text { eq }}$ is the value of ozone concentration in photochemical equilibrium from Reaction (R1). We also calculated the ratio of ozone losses in Reactions (R2) and (R3). In order to remove transition regions that correspond to sunset and sunrise, we take into account the local time when the solar zenith angle $\chi<80^{\circ}$. Previous research, based on satellite measurements, most often shows the results at pressure heights, or "pseudo altitudes". Following these, in the present paper we represent our results at pressure heights $z^{*}=-H \ln \left(p / p_{0}\right)$, where $H=7 \mathrm{~km}$ is the scale height, $p$ is the pressure and $p_{0}=1013 \mathrm{hPa}$ is the pressure at the surface.

\section{Results and discussion}

Figure 1 shows monthly mean height-latitude cross sections of the relative deviation $\left(\mathrm{O}_{3} / \mathrm{O}_{3 \mathrm{eq}}-1\right)$ for each month averaged over daytime hours. Through the entire year, ozone stays in photochemical equilibrium above $\sim 90 \mathrm{~km}$ with the relative deviation of less than $1 \%$. Deviations of ozone from photochemical equilibrium in the extended mesopause region occur with a maximum of $3-4 \%$ at $80-85 \mathrm{~km}$. The height of this area has an annual variation, with a maximum deviation in the winter hemisphere and smooth transitions from one hemisphere to another during spring and autumn. Generally, through the entire region comprising 75-100 km, one can assume that ozone stays in photochemical equilibrium and the deviation does not exceed 3-4\% under daytime conditions. 

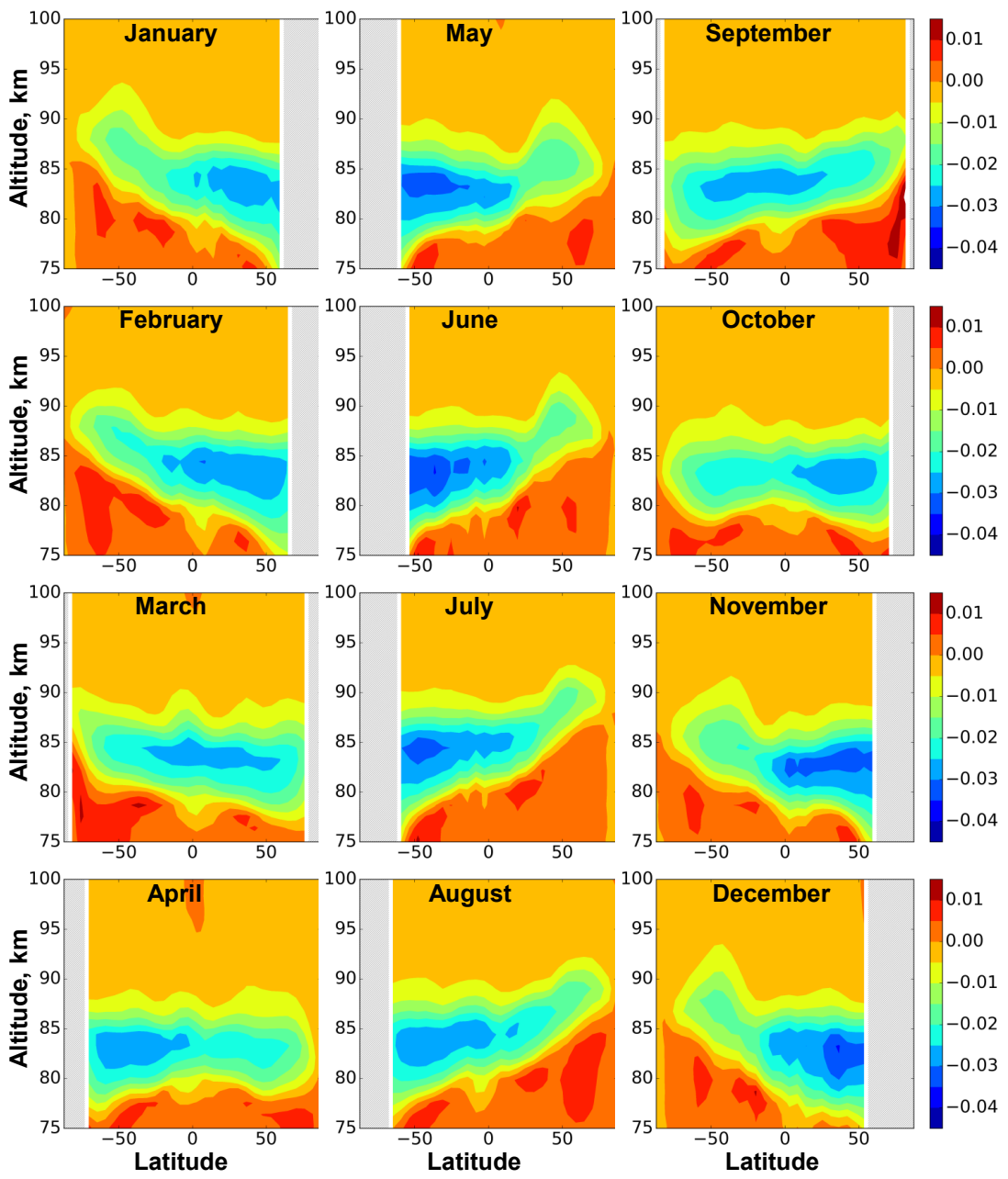

Figure 1. Daytime mean monthly averaged $\mathrm{O}_{3} / \mathrm{O}_{3 \text { eq }}-1$.

Figure 2 shows daytime mean monthly averaged heightlatitude cross sections for the ratio of Reactions (R2) and (R3), i.e., $R=k_{2} \cdot H / J_{\mathrm{O}_{3}}$. The black solid line and dashed line designate areas where this ratio equals 0.1 and 0.3 , respectively, i.e., where the loss of ozone due to reactions with atomic hydrogen amounts to 10 and $30 \%$ of the dissociation loss of ozone, respectively. Evidently, the area where $R>0.1$ is essential for all seasons and composes more than half of the total area between 75 and $100 \mathrm{~km}$. The maxima of the ratio are placed at $85-90 \mathrm{~km}$ in equatorial and low latitudes and amount to $0.2-0.7$, depending on the season. The ratio is greatest in January-February and in June-July because the level of net dissociation is reduced near the solstices. The lowest values of the ratio appear in April and October, where the daily net incoming solar radiation is maximized and tides in the equatorial mesopause produce high values of atomic hydrogen. One can see that Reaction (R3) composes the essential branch of ozone losses and should not be omitted for daytime conditions at all latitudes throughout the entire year.
Figure 3 shows daytime averaged annual mean heightlatitude cross sections for the ratio $R$. Comparison of this figure with the SABER results demonstrates how the uncertainty due to omitting Reaction (R3) may modify the observed values. For example, according to SABER (Fig. 5 in Mlynczak et al., 2013), atomic oxygen concentration below $\sim 92 \mathrm{~km}$ has an almost uniform meridional distribution. But taking Reaction (R3) into account, one can see that the maximum of $O$ concentration should exist at $84-92 \mathrm{~km}$ for low and equatorial latitudes. This may result in corrections to the reported levels of exothermic chemical heat, which are calculated through the retrieval of atomic oxygen (Mlynczak et al., 2007), as well as in higher values for the night-to-day ratio and diurnal variation of atomic oxygen (Fig. 5, Smith et al., 2010). More detailed analysis is needed for each particular measurement and is beyond the scope of this work. 

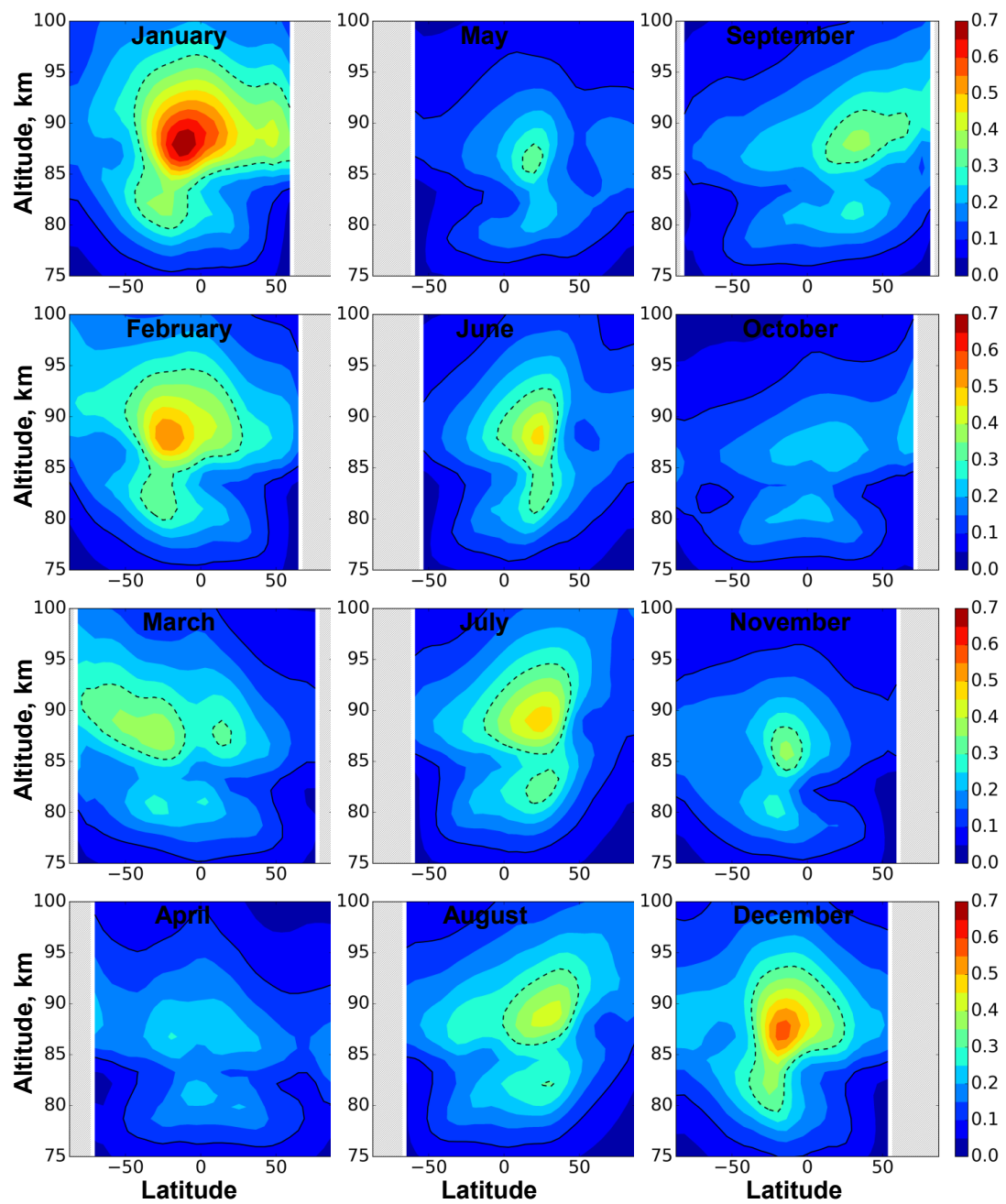

Figure 2. Daytime mean monthly averaged $R$.

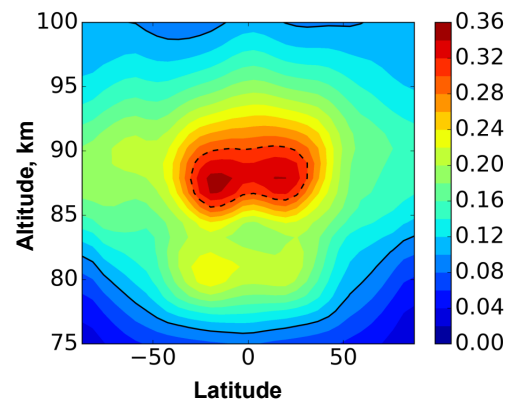

Figure 3. Daytime mean annually averaged $R$.

\section{Conclusions}

By 3-D modeling, we prove that ozone almost always stays in photochemical equilibrium in the extended mesopause region during daytime hours.
The results discussed in Sect. 3 allow us to draw the following conclusions on the relative significance of ozone losses and the atomic oxygen concentration uncertainty due to omitting Reaction (R3):

1. In most of the $75-100 \mathrm{~km}$ region, the uncertainty due to omitting Reaction (R3), $\delta \mathrm{O} / \mathrm{O}$, exceeds $10 \%$; hence, it should not be ignored.

2. Areas where $\delta \mathrm{O} / \mathrm{O}$ is comparable to or higher than the uncertainty of ozone measurements and the rate of $\mathrm{Re}$ action $(\mathrm{R} 1)(\sim 20 \%)$ exist throughout the entire year.

3. $\delta \mathrm{O} / \mathrm{O}$ amounts to $50-70 \%$ at maxima.

Hence, the reaction of ozone with atomic hydrogen is found to be an important loss process and should not be omitted.

Data availability. The data used in this study are supported by the Institute of Applied Physics of the Russian Academy of Sciences 
(Nizhny Novgorod, Russia) and inquiries about calculated distributions used for this paper can be addressed to Mikhail V. Belikovich (belikovich@ipfran.ru).

Competing interests. The authors declare that they have no conflict of interest.

Acknowledgements. This work was supported by the Russian Science Foundation (contract no. 15-17-10024, 4 June 2015).

The topical editor, C. Jacobi, thanks one anonymous referee for help in evaluating this paper.

\section{References}

Allen, M., Lunine, J. I., and Yung, Y. L.: The Vertical Distribution of Ozone in the Mesosphere and Lower Thermosphere, J. Geophys. Res., 89, 4841-4872, 1984

de Grandpre, J., Beagley, S. R., Fomichev, V. I., Griffioen, E., McConnell, J. C., Medvedev, A. S., and Shepherd. T. G.: Ozone climatology using interactive chemistry: Results from the Canadian Middle Atmosphere Model, J. Geophys. Res., 105, 2647526491, 2000.

Evans, W. F. J. and Llewellyn, E. J.: Atomic hydrogen concentrations in the mesosphere and the hydroxyl emissions, J. Geophys. Res., 78, 323-326, doi:10.1029/JA078i001p00323, 1973.

Evans, W. F. J., McDade, I. C., Yuen, J., and Llewellyn, E. J.: A rocket measurement of the $\mathrm{O}_{2}$ infrared atmospheric $(0-0)$ band emission in the dayglow and a determination of the mesospheric ozone and atomic oxygen densities, Can. J. Phys., 66, 941-946, 1988.

Grygalashvyly, M., Sonnemann, G. R., and Hartogh, P.: Long-term behavior of the concentration of the minor constituents in the mesosphere - a model study, Atmos. Chem. Phys., 9, 2779-2792, doi:10.5194/acp-9-2779-2009, 2009.

Grygalashvyly, M., Becker, E., and Sonnemann, G. R.: Wave mixing effects on minor chemical constituents in the MLT region: Results from a global CTM driven by high-resolution dynamics, J. Geophys. Res., 116, D18302, doi:10.1029/2010JD015518, 2011.

Grygalashvyly, M., Becker, E., and Sonnemann, G. R.: Gravity wave mixing and effective diffusivity for minor chemical constituents in the mesosphere/lower thermosphere, Space Sci. Rev., 168, 333-362, doi:10.1007/s11214-011-9857-x, 2012.

Grygalashvyly, M., Sonnemann, G. R., Lübken, F.-J., Hartogh, P., and Berger, U.: Hydroxyl layer: Mean state and trends at midlatitudes, J. Geophys. Res., 119, 12391-12419, doi:10.1002/2014JD022094, 2014.

Hartogh, P., Jarchow, C., Sonnemann, G. R., and Grygalashvyly, M.: On the spatiotemporal behavior of ozone within the upper mesosphere/mesopause region under nearly polar night conditions, J. Geophys. Res., 109, D18303, doi:10.1029/2004JD004576, 2004.

Hartogh, P., Sonnemann, G. R., Grygalashvyly, M., and Jarchow, Ch.: Ozone trends in mid-latitude stratopause region based on microwave measurements at Lindau $\left(51.66^{\circ} \mathrm{N}, 10.13^{\circ} \mathrm{E}\right)$, the ozone reference model, and model calculations, Adv. Space Res., 47, 1937-1948, doi:10.1016/j.asr.2011.01.010, 2011.

Körner, U. and Sonnemann, G. R.: Global 3D-modeling of water vapor concentration of the mesosphere/mesopause region and implications with respect to the NLC region, J. Geophys. Res., 106, 9639-9651, 2001.

Kulikov, M. Y., Feigin, A. M., and Sonnemann, G. R.: Retrieval of the vertical distribution of chemical components in the mesosphere from simultaneous measurements of ozone and hydroxyl distributions, Radiophys. Quantum El., 49, 683-691, doi:10.1007/s11141-006-0103-4, 2006.

Kulikov, M. Y., Feigin, A. M., and Sonnemann, G. R.: Retrieval of water vapor profile in the mesosphere from satellite ozone and hydroxyl measurements by the basic dynamic model of mesospheric photochemical system, Atmos. Chem. Phys., 9, 81998210, doi:10.5194/acp-9-8199-2009, 2009.

Kulikov, M. Yu., Belikovich, M. V., Grygalashvyly, M., Sonnemann, G. R., Ermakova, T. S., Nechaev, A. A., and Feigin, A M.: Nighttime ozone chemical equilibrium in the mesopause region, J. Geophys. Res., submitted, 2017.

Moreels, G., Megie, A., Vauance J., and Gatmnger, R. L.: An oxygen-hydrogen atmospheric model and its application to the OH emission problem, Atmos. Terr. Phys., 39, 551-570, 1977.

Mlynczak, M. G., Marshall, B. T., Martin-Torres, F. J., Russell III, J. M., Thompson, R. E., Remsberg, E. E., and Gordley, L. L.: Sounding of the Atmosphere using Broadband Emission Radiometry observations of daytime mesospheric $\mathrm{O}_{2}\left({ }^{1} \mathrm{D}\right) 1.27 \mu \mathrm{m}$ emission and derivation of ozone, atomic oxygen, and solar and chemical energy deposition rates, J. Geophys. Res., 112, D15306, doi:10.1029/2006JD008355, 2007.

Mlynczak, M. G., Hunt, L. A., Mast, J. C., Marshall, B. T., Russell III, J. M., Smith, A. K., Siskind, D. E., Yee, J.-H., Mertens, C. J., Martin-Torres, F. J., Thompson, R. E., Drob, D. P., and Gordley, L. L.: Atomic oxygen in the mesosphere and lower thermosphere derived from SABER: Algorithm theoretical basis and measurement uncertainty, J. Geophys. Res., 118, 5724-5735, doi:10.1002/jgrd.50401, 2013a.

Mlynczak, M. G., Hunt, L. H., Mertens, C. J., Marshall, B. T., Russell III, J. M., López-Puertas, M., Smith, A. K., Siskind, D. E., Mast, J. C., Thompson, R. E., and Gordley, L. L.: Radiative and energetic constraints on the global annual mean atomic oxygen concentration in the mesopause region, J. Geophys. Res.-Atmos., 118, 5796-5802, doi:10.1002/jgrd.50400, 2013b.

Mlynczak, M. G., Hunt, L. H., Marshall, B. T., Mertens, C. J., Marsh, D. R., Smith, A. K., Russell, J. M., Siskind, D. E., and Gordley, L. L.: Atomic hydrogen in the mesopause region derived from SABER: Algorithm theoretical basis, measurement uncertainty, and results, J. Geophys. Res., 119, 3516-3526, doi:10.1002/2013JD021263, 2014.

Pendleton, W. R., Baker, K. D., and Howlett, L. C.: Rocket-based investigations of $\mathrm{O}\left({ }^{3} \mathrm{P}\right), \mathrm{O}_{2}\left(\mathrm{a}^{1} \Delta_{g}\right)$ and $\mathrm{OH}^{*}(v=1,2)$ during the solar eclipse of 26 February (1979), J. Atmos. Terr. Phys., 45, 479-491, 1983.

Scinocca, J. F., McFarlane, N. A., Lazare, M., Li, J., and Plummer, D.: Technical Note: The CCCma third generation AGCM and its extension into the middle atmosphere, Atmos. Chem. Phys., 8, 7055-7074, doi:10.5194/acp-8-7055-2008, 2008.

Siskind D. E., Mlynczak, M. G., Marshall, T., Friedrich, M., and Gumbel, J.: Implications of odd oxygen observations by the 
TIMED/SABER instrument for lower D region ionospheric modeling, J. Atmos. Sol.-Terr. Phy., 124, 63-70, 2015.

Smith, A. K. and Marsh, D. R.: Processes that account for the ozone maximum at the mesopause, J. Geophys. Res., 110, D23305, doi:10.1029/2005JD006298, 2005.

Smith, A. K., Marsh, D. R., Russell III, J. M., Mlynczak, M. G., Martin Torres, F. J., and Kyrölä, E.: Satellite observations of high nighttime ozone at the equatorial mesopause, J. Geophys. Res., 113, D17312, doi:10.1029/2008JD010066, 2008.

Smith, A. K., Marsh, D. R., Mlynczak, M. G., and Mast, J. C.: Temporal variations of atomic oxygen in the upper mesosphere from SABER, J. Geophys. Res., 115, D18309, doi:10.1029/2009JD013434, 2010.

Sonnemann, G., Kremp, C., Ebel, A., and Berger, U.: A threedimensional dynamic model of minor constituents of the mesosphere, Atmos. Environ., 32, 3157-3172, doi:10.1016/S13522310(98)00113-7, 1998.

Sonnemann, G. R., Grygalashvyly, M., Hartogh, P., and Jarchow, C.: Behavior of mesospheric ozone under nearly polar night conditions, Adv. Space Res., 38, 2402-2407, 2006a.
Sonnemann, G. R., Hartogh, P., Jarchow, C., Grygalashvyly, M., and Berger, U.: The winter anomaly of the night-to-day ratio of ozone in the middle to upper mesosphere in middle latitudes: A comparison between measurements and model calculations, Adv. Geosci., 9, 177-190, 2006 b.

Sonnemann, G. R., Hartogh, P., Jarchow, C., Grygalashvyly, M., and Berger, U.: On the winter anomaly of the night-to-day ratio of ozone in the middle to upper mesosphere in middle to high latitudes, Adv. Space Res., 40, 846-854, 2007.

Sonnemann, G. R., Hartogh, P., Berger, U., and Grygalashvyly, M.: Hydroxyl layer: trend of number density and intra-annual variability, Ann. Geophys., 33, 749-767, doi:10.5194/angeo-33-7492015, 2015.

Thomas, R. J.: Atomic hydrogen and atomic oxygen density in the mesosphere region: Global and seasonal variations deduced from Solar Mesosphere Explorer near-infrared emissions, J. Geophys. Res., 95, 16457-16476, 1990. 